\title{
ARTICLE
}

\section{Maintenance of water uptake and reduced water loss contribute to water stress tolerance of Spiraea alba Du Roi and Spiraea}

\section{tomentosa L.}

\author{
Kelly M Stanton and Michael V Mickelbart
}

Two primarily eastern US native shrubs, Spiraea alba Du Roi and Spiraea tomentosa L., are typically found growing in wet areas, often with standing water. Both species have potential for use in the landscape, but little is known of their environmental requirements, including their adaptation to water stress. Two geographic accessions of each species were evaluated for their response to water stress under greenhouse conditions. Above-ground biomass, water relations and gas exchange were measured in well-watered and water stress treatments. In both species, water stress resulted in reduced growth, transpiration and pre-dawn water potential. However, both species also exhibited the ability to osmotically adjust to lower soil water content, resulting in maintained midday leaf turgor potential in all accessions. Net $\mathrm{CO}_{2}$ assimilation was reduced only in one accession of $\mathrm{S}$. alba, primarily due to large reductions in stomatal conductance. S. tomentosa lost a larger proportion of leaves than S. alba in response to water stress. The primary water stress tolerance strategies of $S$. alba and $S$. tomentosa appear to be the maintenance of water uptake and reduced water loss.

Horticulture Research (2014) 1, 14033; doi:10.1038/hortres.2014.33; Published online: 23 July 2014

\section{INTRODUCTION}

The managed landscape presents a number of biotic and abiotic stresses for plants. These include high and/or low light, nutrient deficiency and/or excess, and water deficit due to inadequate rainfall and/or irrigation, soil compaction and impermeable surfaces above the root zone. ${ }^{1,2}$ Transplanted seedlings and plants are often exposed to water stress immediately after planting and this stress can result in poor establishment and sometimes mortality. ${ }^{3}$

Plant response to water deficit is dependent on the level of the deficit, but growth and survival can be achieved through desiccation avoidance or tolerance. ${ }^{4}$ Desiccation tolerance, or tolerance of low water potential, often results in plant responses such as wilting that are not desired in plants used in gardens and landscapes. ${ }^{5}$ Desiccation avoidance strategies allow for avoidance of low plant water potentials by reducing water loss or increasing water uptake, accomplished via reduced stomatal aperture, reduced leaf area and/or osmotic adjustment. ${ }^{6}$ These responses are more likely to be tolerated in landscape plantings, but the degree to which reduced leaf area is achieved through leaf abscission and/or senescence is also an important factor.

There is growing interest in gardening with native plants not only for their novelty, but also to take advantage of their adaptation to local climates..$^{7-9}$ Drought events are increasing in frequency in the United States ${ }^{10}$ and the identification of native species capable of maintaining their appearance in a formal landscape under water stress conditions is important to both the landscape production and maintenance industry and consumers. ${ }^{11-13}$ This has led to renewed interest in documenting water use of both native and exotic landscape plants. ${ }^{14-16}$ However, most species recommendations are made based on anecdotal evidence and not systematic and/or comparative studies of water stress tolerance.

The native shrubs Spiraea alba Du Roi and Spiraea tomentosa L. have potential as landscape plants due to their relatively small size (1-1.5 $\mathrm{m}$ tall) and their long and showy flowering period. ${ }^{17} \mathrm{~S}$. tomentosa was used in the landscape as early as $1736 .^{18}$ Both species are now mainly used in habitat restoration, although there is revived interest in their use as landscape plants. $^{19,20}$ Both S. alba and S. tomentosa are often found thriving in sites with saturated soils ${ }^{21-24}$ or periodic flooding ${ }^{25-28}$ and therefore, they are recommended for wet landscape sites. ${ }^{29}$ They are adapted to a wide range of soils, including serpentine soils, ${ }^{30}$ but their salt tolerance is unclear. $^{31,32}$ There is some indication that both species can be grown in dry soils; ${ }^{33-36}$ however, water stress tolerance has not been evaluated in these species.

Water stress responses were determined in S. alba and S. tomentosa following a dry-down period under controlled conditions. Growth, water relations and gas exchange were used to determine the relative water stress tolerance of these two species and of two Midwest accessions within each species.

\section{MATERIALS AND METHODS}

\section{Design and analysis}

The goal of this experiment was to test differences in growth and physiology of two seed source accessions (Illinois $=\mathrm{IL}$ and Michigan=MI) of each of S. alba and S. tomentosa grown under well-watered (WW) or water stress (WS) treatments. The experiment was arranged as a split-plot on a randomized complete block design. Each of six blocks consisted of two treatments (subplots): one WW and one WS container in which one replicate of each of the species and accessions within species (four plants total: one plant $\times$ treatment replicate each) was randomized within each subplot (Supplementary Figure S1). Two-way analysis of variance was conducted to determine significant differences between treatments and among accessions with treatment (water) and accession as fixed effects and block as a random effect using PROC GLIMMIX of the statistical software SAS 9.2 (SAS Inc., Cary, NC, USA). 
Plant materials and growth conditions

All plants were grown from seed germinated in the spring of 2008 by collaborating commercial nurseries and provided as plugs or grown from seed planted in spring of 2008 in the Purdue Horticulture greenhouses. S. alba and S. tomentosa were grown from seed collected in Will County, Illinois and Jackson County, Michigan. Each accession was given a unique abbreviation: the first letter indicates species $(A=S$. alba and $T=S$. tomentos $a)$ and the next two letters are the postal code of the state in which the seed for that accession was collected (IL=Illinois and $\mathrm{Ml}=$ Michigan).

Uniform plugs of all plants were planted on 13 February 2009. One plant of each accession was planted in Fafard ${ }_{\circledast}$ Growing Mix 2 soilless media (Conrad Fafard, Inc., Agawam, MA, USA) in a $0.6 \mathrm{~m} \times 0.9 \mathrm{~m} \times 0.2 \mathrm{~m}$ (ca $0.108 \mathrm{~m}^{3}$ media) black plastic container (Shape Products, LLC, Menomonie, WI, USA) with holes drilled to allow drainage of the media, allowing for direct comparison of genotypes under similar media water content (Supplementary Figure S1). After planting, plants were pruned to $10 \mathrm{~cm}$ from media level and containers were irrigated to field capacity with a significant leaching fraction. On 14 July, all containers were irrigated (the last irrigation for WS treatments) and all plants were pruned to $17 \mathrm{~cm}$ from media level. The WW containers were irrigated three more times (sufficient to maintain growth given the large volume of the containers used) and the last irrigation was on 27 August, the day before final measurements were made.

Plants were fertilized with acidified water supplemented with $15 \mathrm{~N}-2.2 \mathrm{P}-$ 12.5K water-soluble fertilizer (Excel Cal-Mag; Scotts, Marysville, OH, USA) to provide the following (in $\mathrm{mg} \mathrm{L}^{-1}$ ): $200 \mathrm{~N}, 29 \mathrm{P}, 167 \mathrm{~K}, 67 \mathrm{Ca}, 27 \mathrm{Mg}, 1.0 \mathrm{Fe}, 0.5$ $\mathrm{Mn}$ and $\mathrm{Zn}, 0.24 \mathrm{Cu}$ and $\mathrm{B}$, and $0.1 \mathrm{Mo}$. Irrigation water was supplemented with $93 \%$ sulfuric acid (Ulrich Chemical, Indianapolis, IN, USA) at $0.08 \mathrm{~mL} \mathrm{~L}^{-1}$ to reduce alkalinity to $100 \mathrm{mg} \mathrm{L}^{-1}$ and $\mathrm{pH}$ to a range of 5.7-6.3.

The greenhouse day and night mean temperatures were 22 and $18{ }^{\circ} \mathrm{C}$, respectively, and maximum day and night $\mathrm{RH}$ was ca $60 \%$ and $50 \%$, respectively. To provide a 16-h photoperiod throughout the experiment, supplemental lighting from metal halide and high pressure sodium lamps contributed $100 \mu \mathrm{mol} \mathrm{m} \mathrm{m}^{-2} \mathrm{~s}^{-1}$ at plant height from $0600 \mathrm{HR}$ to $2200 \mathrm{HR}$.

\section{Measurements}

Gas exchange was measured on all plants 16 days before and 45 days after cessation of irrigation in the WS treatment on a recently developed, fully expanded leaf using a Li-Cor 6400XT (Li-Cor, Inc., Lincoln, NE, USA). Measurements were made between $1000 \mathrm{HR}$ and $1400 \mathrm{HR}$, using an external light source set at $1500 \mu \mathrm{mol} \mathrm{m} \mathrm{m}^{-2} \mathrm{~s}^{-1}$ and a flow rate of $400 \mu \mathrm{mol} \mathrm{s}{ }^{-1}$. The vapor pressure deficit during measurements was between 0.7 and $1.5 \mathrm{kPa}$. Because the leaves were too small to fill the chamber opening, leaves were photographed in the chamber prior to measurements, leaf area was calculated using Image $\mathrm{J} \times 1.38$ (National Institutes of Health, Bethesda, MD, USA), and gas exchange values were adjusted accordingly. For each measurement, the leaf was positioned on the thermocouple in the chamber to ensure accurate measurement of leaf temperature for calculation of stomatal conductance. In addition to plants grown for the water stress treatment, an additional set of plants grown from seed collected in northern Indiana were used to measure photosynthetic light curves.

Chlorophyll fluorescence was measured on recently matured, fully expanded, dark-adapted leaves 1 day prior to gas exchange measurements using a Hansatech Handy PEA chlorophyll fluorometer (Hansatech Instruments Ltd, Norfolk, UK). Leaves were dark adapted for 15 min prior to measurements, based on preliminary tests of dark adaptation time. The ratio of variable to maximum fluorescence $\left(F_{\mathrm{v}} / F_{\mathrm{m}}\right)$ was used as an indicator of the maximum quantum efficiency of photosystem II.

All water relations measurements were made pre-dawn (ca 0200-0600 HR) and midday (ca 1100-1400 HR). Plant water potential (pre-dawn $\Psi_{w}$ and midday $\left.\Psi_{w}\right)$ was measured on stems $(c a 10 \mathrm{~cm})$ that included $c a 13$ leaves, three of which were fully expanded. Each stem was cut from the plant with a sharp razor blade and inserted into a rubber stopper, which was then placed in a pressure chamber (PMS Instrument Company, Corvallis, OR, USA) for determination of total water potential.

Leaf osmotic potential was determined on leaves from the same stem used for the total water potential measurements. One to two fully expanded leaves were removed from each shoot and placed in a mesh insert (Life Science Products, Inc., Frederick, CO, USA) inserted in a microcentrifuge tube and immersed in liquid nitrogen until completely frozen. They were then kept on ice until they could be stored at $-20{ }^{\circ} \mathrm{C}$ until processing. To extract cell sap, leaves were thawed in sealed tubes for $20 \mathrm{~min}$ and centrifuged at 13000 r.p.m. for $10 \mathrm{~min}$. Ten microliters of the extracted liquid was placed in a vapor pressure osmometer (Wescor 5500; Wescor Inc., Logan, UT, USA).
The osmolality was converted to osmotic potential by the equation $\Psi_{\pi}=-C_{\mathrm{s}} R T$, where $\Psi_{\pi}$ is osmotic potential, $C_{\mathrm{s}}$ is the osmolality, $R$ is the gas constant and $T$ is temperature. The osmotic potential at full turgor $\left(\Psi_{\pi 100}\right)$ was calculated as $\Psi_{\pi} \times$ RWC (defined below).

Relative water content (RWC) was determined on a fully expanded leaf from the stem that was used for the total water potential measurements. A scintillation vial was filled with $5 \mathrm{~mL}$ of de-ionized water and weighed. As each leaf was cut from the plant, it was immediately placed in a vial with the petiole down and the difference in weight provided the leaf fresh weight (LFW). The leaves were left to imbibe water for $5 \mathrm{~h}$ before they were removed, quickly blotted dry to remove surface water and weighed to obtain the leaf turgid weight (LTW). The leaves were then dried to a constant weight at $70{ }^{\circ} \mathrm{C}(\mathrm{LDW})$. Relative water content was calculated as RWC $=(\mathrm{LFW}-$ $\mathrm{LDW} /(\mathrm{LTW}-\mathrm{LDW})$. Leaf succulence was calculated as LFW/LDW.

After determination of LTW, the leaf used for determining RWC was photographed next to a ruler with a digital camera prior to drying. Leaf area (LA) was determined using ImageJ $\times 1.38$ software (National Institutes of Health, Bethesda, MD, USA). Specific leaf area (SLA) was calculated as SLA =LA/LDW.

Media water content was determined immediately after completion of gas exchange and water relations measurements from a media core $4 \mathrm{~cm}$ in diameter extending from the surface of the media to the bottom of each container. The media samples were placed into sealed containers of known weight and weighed (MFW). The media was then dried to a constant weight at $70{ }^{\circ} \mathrm{C}$ (MDW). Percent media water content was calculated as $\mathrm{MWC}=((\mathrm{MFW}-\mathrm{MDW}) / \mathrm{MFW}) \times 100$.

After all physiological measurements were completed, the plants were cut at media level and above-ground biomass was dried to a constant weight at $70{ }^{\circ} \mathrm{C}$ for determination of total above-ground dry weight. Most of the leaves that died during the experiment remained attached to the plants and were thus included in dry weight values.

\section{RESULTS}

Media water content

Media water content among the six control (WW) containers was very consistent at $77.7 \% \pm 0.1 \%$ (mean \pm s.e.). The MWC of the WS containers was significantly different from the WW containers $(p<0.0001)$, but the variability among WS containers was high $(38.8 \% \pm 4.6 \%)$ after 45 days of water stress (Supplementary Figure S1). Among WS containers, MWC of blocks $1-3$ averaged $29.2 \% \pm 2.1 \%$, whereas the MWC of blocks 4-6 averaged $48.5 \% \pm 2.9 \%$. This difference in MWC within the WS treatment was not due to larger plants in blocks $1-3$, potentially leading to greater transpirational water loss (no significant differences in above-ground dry weight among blocks), but is likely due to differences in light across the experiment. However, the split plot design allowed for direct comparison of accessions within a single subplot, so that all plants in that subplot would be subjected to approximately the same MWC. It should be noted that MWC was only collected at the end of the experiment, so while it does confirm differences between treatments and indicate differences among plots, the amount of time the plants were growing under these different MWC conditions is not known.

\section{Growth}

After 45 days without irrigation, a greater proportion of older leaves had senesced on $S$. tomentosa plants than $S$. alba plants, based on visual observations (Figure 1). Within S. alba, the Michigan accession appeared to have greater senescence and more leaf loss than A-IL, whereas differences between the $S$. tomentosa accessions were less obvious (Figure 1). Individual leaf area was not affected by WS, except in A-IL, in which leaves that developed during the WS were ca $60 \%$ the size of WW leaves (Supplementary Figure S2), and the average SLA was $283 \mathrm{~cm}^{2} \mathrm{~g}^{-1}$, with no differences between accessions and/or treatments. Although individual leaf area was reduced by water stress only in A-IL plants, total above-ground biomass was lower in WS plants in all accessions except T-MI (Figure 2), suggesting that leaf initiation was suppressed in plants exposed to WS. It is important to note that plant biomass included senesced leaves that remained on the plants at the time of harvest (Figure 1). 


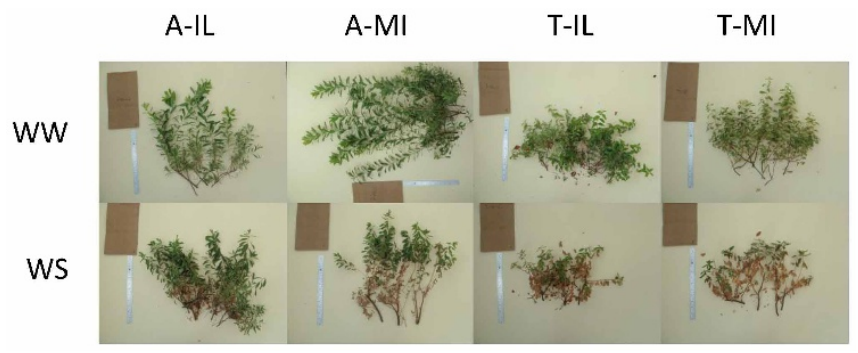

Figure 1. Representative photographs of $S$. alba and S. tomentosa accessions from Illinois (A-IL and T-IL) and Michigan (A-MI and T-MI) exposed to well-watered (WW) or 45 days of water-stress (WS) treatments.

Water relations

All water relations measurements were collected at predawn (ca 0200-0600 HR) to assess the water status of plants at equilibrium when transpirational demand should be minimal and at midday ( $c a$ 1000-1400 HR) to assess the relative effects of WS on the accessions of the two species. Midday RWC decreased in response to WS in leaves of all accessions (Figure 3). Leaf RWC recovered overnight in WS plants of all accessions so there was no difference between WW and WS plants at predawn (data not shown). Leaf succulence did not change significantly between predawn and midday periods and was $3.01 \pm 0.34$ overall. Although WS resulted in lower RWC, midday succulence was different between WW (3.27 \pm 0.17$)$ and WS $(2.74 \pm 0.05)$ plants only in A-MI, presumably because RWC was still relatively high in WS plants.

Water stress resulted in reduced predawn $\Psi_{\mathrm{w}}$ in all accessions (Figure 4a), whereas midday $\Psi_{w}$ was lower in response to WS only in S. alba accessions (Figure $4 \mathrm{~b}$ ). Differences in $\Psi_{\mathrm{w}}$ between WW and WS plants in blocks 4-6 were much less than in blocks 1-3, likely due to differences in MWC described above.

The patterns of leaf $\Psi_{\pi}$ and $\Psi_{\pi 100}$ were similar among accessions and treatments, so only $\Psi_{\pi 100}$ is presented to demonstrate osmotic adjustment (i.e., corrected for leaf water content). Leaf $\Psi_{\pi}$ did not differ between predawn and midday periods in any accessions, and WS plants had lower $\Psi_{\pi}$ in all cases (data not shown). When $\Psi_{\pi}$ was

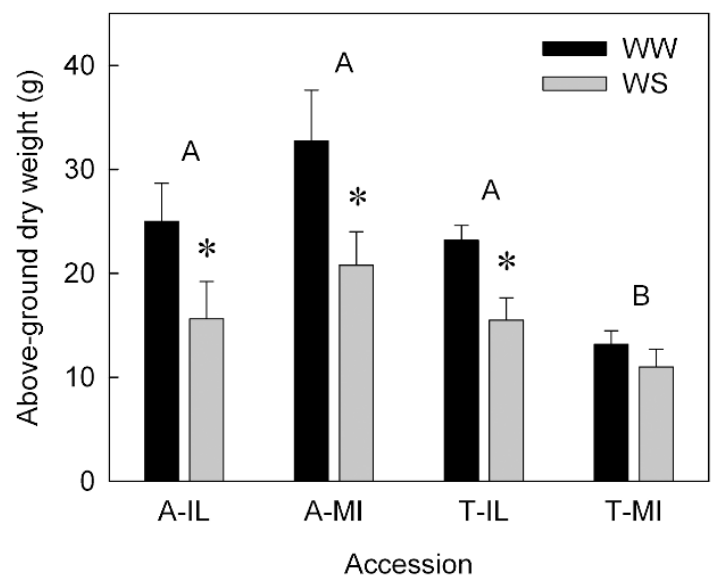

Figure 2. Above-ground dry weight of S. alba and S. tomentosa accessions from Illinois (A-IL and T-IL) and Michigan (A-MI and T-MI) exposed to well-watered (WW, black columns) or 45 days of waterstress (WS, gray columns) treatments. Columns are means $(n=6)$ and bars are \pm s.e. Asterisks above pairs of columns indicate significant differences between treatments within an accession at $* p<0.05$. Accessions (pairs of columns) with the same letter are not significantly different based on Tukey's Honestly Significant Different Test.

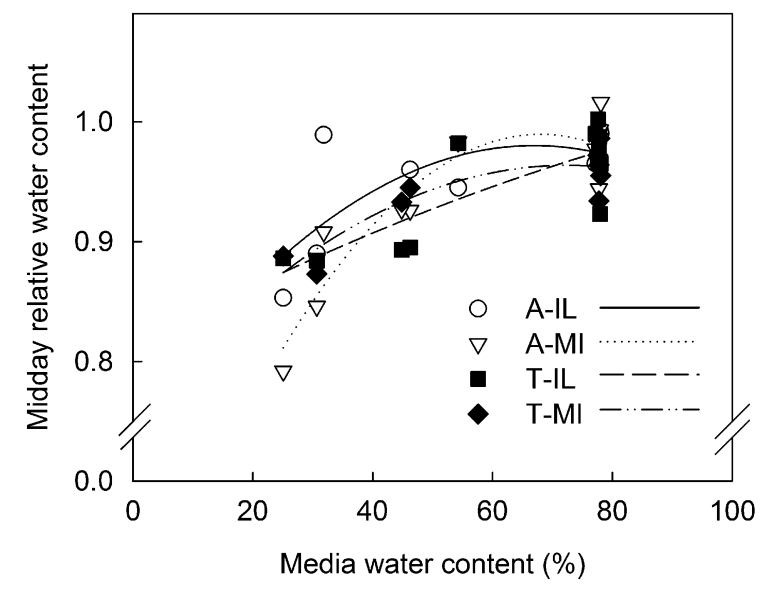

Figure 3. Relationship between media water content and midday RWC. The relationship was quadratic for Illinois $\left(y=-0.519 x^{2}+\right.$ $\left.0.6969 x+0.746 ; R^{2}=0.5441\right)$ and Michigan $\left(y=-0.97 x^{2}+1.319 x+\right.$ $\left.0.5413 ; R^{2}=0.8707\right)$ accessions of $S$. alba (A-IL and A-MI) and the Michigan $\left(y=-0.4031 x^{2}+0.5817 x+0.7536 ; R^{2}=0.8012\right)$ accession of S. tomentosa (T-MI) and linear for the Illinois $(y=0.1853 x+0.8314$; $R^{2}=0.6679$ ) accession of $S$. tomentosa (T-IL).

adjusted for RWC to calculate $\Psi_{\pi 100}$, the same pattern was evident: all accessions responded to WS with a lower $\Psi_{\pi 100}$ (Figure $4 \mathrm{c}$ and 4d).

In all plants and at both predawn and midday, $\Psi_{\pi 100}$ (and $\Psi_{\pi}$ ) was lower than $\Psi_{w}$, which resulted in maintained leaf turgidity $\left(\Psi_{\mathrm{p}}\right)$ in all accessions (Figure 4e and 4f). The fact that RWC was lower in WS plants and that the osmotic potential corrected for RWC $\left(\Psi_{\pi 100}\right)$ was lower in all cases suggests that osmotic adjustment occurs in both species. The predawn osmotic adjustment (difference in $\Psi_{\pi 100}$ between WS and WW plants) in A-IL, A-MI, T-IL and T-MI was 0.70, $0.50,0.72$ and $0.63 \mathrm{MPa}$, respectively. Calculated midday values were similar among accessions, but lower due to the reduction in midday RWC.

Gas exchange and chlorophyll fluorescence

In response to WS, net $\mathrm{CO}_{2}$ assimilation was reduced by $60 \%$ of WW plants in A-Ml, but was not reduced in any other accessions (Figure 5a). Transpiration and stomatal conductance were both lower in WS plants with no differences among accessions (Figure $5 \mathrm{~b}$ and $5 \mathrm{c}$ ). In the WW treatment, $F_{\mathrm{v}} / F_{\mathrm{m}}$ was higher in $S$. alba $(0.800 \pm 0.004)$ than $S$. tomentosa $(0.737 \pm 0.015)$; however, $F_{\mathrm{v}} / F_{\mathrm{m}}$ was not reduced by WS in any of the accessions $(0.776 \pm 0.010)$.

\section{DISCUSSION}

Two accessions each of S. alba and S. tomentosa were grown under greenhouse conditions to assess their response to and mechanisms of water stress tolerance. These species are typically found in wet areas, $^{1,24-28,37}$ so we sought to test the hypothesis that they are able to withstand short periods of water deficit, as anecdotally proposed by others. ${ }^{33-35}$ In previous studies, both species have demonstrated adaptation to light levels ${ }^{38}$ and root zone $\mathrm{pH}^{39}$ that differ from their typical native habitats, and there are examples of other plants native to wet soils that perform suitably under managed landscape systems. ${ }^{16}$

When either of these species is exposed to rapid dry-down, as is typical in small production containers, both S. alba and S. tomentosa exhibit wilting and eventually shoot tip necrosis (personal observations). However, when grown in large containers in this study, the water stress occurred more slowly (over approximately 2 weeks), more resembling natural or landscape conditions and allowing time 


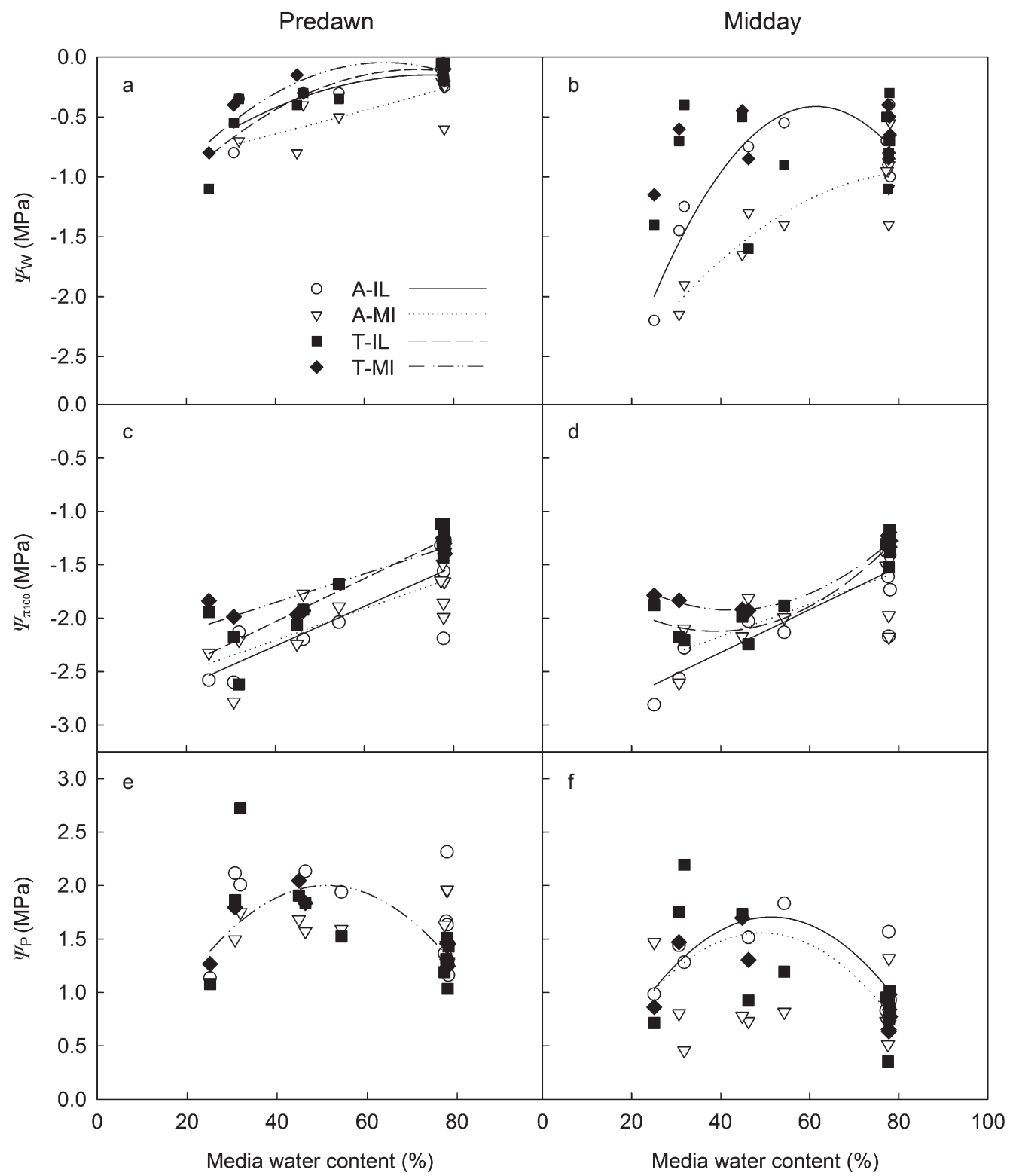

Figure 4. Predawn (a, $\mathbf{c}$ and $\mathbf{e})$ and midday (b, $\mathbf{d}$ and $\mathbf{f})$ water potential $\left(\Psi_{\mathrm{w},} \mathbf{a}\right.$ and $\left.\mathbf{b}\right)$, osmotic potential at full turgor $\left(\Psi_{\pi 100}, \mathbf{c}\right.$ and $\left.\mathbf{d}\right)$ and turgor potential $\left(\Psi_{\mathrm{p}}, \mathbf{e}\right.$ and $\left.\mathbf{f}\right)$ of $S$. alba and S. tomentosa accessions from Illinois (A-IL and T-IL) and Michigan (A-MI and T-MI) as a function of media water content after 45 days of water stress. Significant relationships are indicated by a fitted line.

for adaptation to the water stress. Wilting was not observed under these conditions, and older leaves appeared to be more affected than developing leaves. Both accessions of both species were grown in a fixed media volume, so differences in root characteristics (e.g., rooting depth) could not be expressed.

The general growth response to water stress in these species is a reduction in shoot growth, as opposed to changes at the leaf level: there were no differences between WW and WS plants in individual leaf area (except A-IL), SLA, or succulence. Some species have reduced SLA under water stress, ${ }^{40}$ presumably due to reduced net carbon assimilation. This was not observed in this experiment (data not shown). Total leaf area was reduced in most accessions in response to water stress through reduced growth as indicated by biomass measurements (Figure 2) and leaf senescence (Figure 1). These strategies are typical in water-stressed woody shrubs ${ }^{4,14,41}$ and are often due to an altered allocation of resources from shoots to roots. ${ }^{42}$ The relative reduction in biomass in response to WS was similar in all accessions except T-MI, which had no reduction in growth in response to WS, but was also the smallest accession in the WW treatment (Figure 2). Fast apical growth rates were correlated with water use efficiency and drought tolerance in Prunus rootstocks, ${ }^{43}$ as in this study except for T-MI. Overall, this accession exhibited more leaf senescence (Figure 1), suggesting that this species may be less suited to dry landscape situations.

Reduction in individual leaf area is often a consequence of water deficit, but may also provide an adaptive advantage, due to a smaller boundary layer, allowing for more efficient dissipation of heat through convection and conduction when water stress leads to stomatal closure and a subsequent reduction of evaporative cooling. ${ }^{44}$ Leaves of A-IL were smaller as a consequence of water stress (data not shown), but all accessions were able to maintain relatively high RWC under water stress (Figure 3 ). 

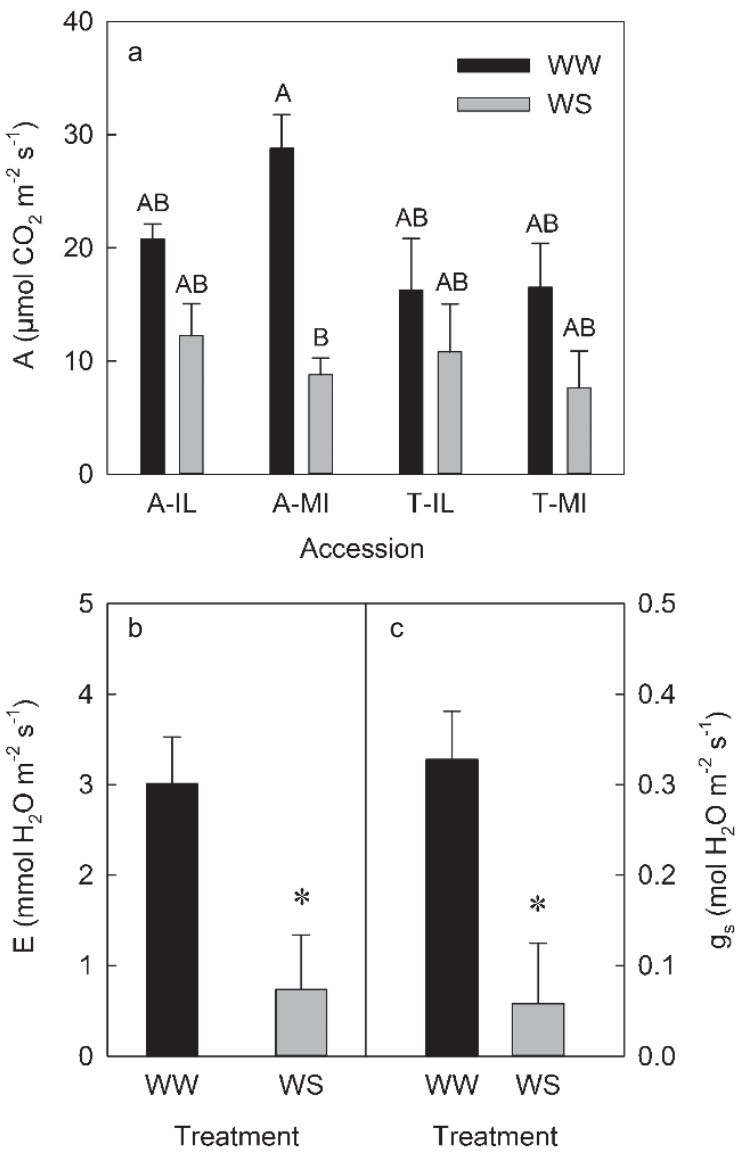

Figure 5. Net $\mathrm{CO}_{2}$ assimilation rate $(A$, a) of $S$. alba and $S$. tomentosa accessions from Illinois (A-IL and T-IL) and Michigan (A-MI and T-MI) exposed to well-watered (WW, black columns) or 45 days of waterstress (WS, gray columns) treatments. Columns are means $(n=4-5)$ and bars are \pm s.e. Transpiration rate $(E, \mathbf{b})$, and stomatal conductance $\left(g_{s}, \mathbf{c}\right)$ of well-watered (WW, black columns) or 45 days of water-stress (WS, gray columns) treatments. Asterisks indicate significant differences between treatments at $* p<0.05$.

In the WW treatment, S. alba and S. tomentosa maintain similar leaf water potentials and stomatal conductance ${ }^{45}$ (Figures $4 \mathrm{~b}$ and 5c). Predawn $\Psi_{\mathrm{w}}$ recovered in both accessions of both species, but in all cases, WS plants were not able to fully recover to control plant values (Figure 4a), suggesting that, regardless of differences in adaptation, all plants were under water deficit stress. The midday $\Psi_{\mathrm{w}}$ of the WS plants in this study were well above levels typically resulting in mortality in woody plant species, but low enough in $S$. alba plants to result in reduced shoot extension as others have also demonstrated. ${ }^{3}$

Young leaves typically maintain lower water potential than older leaves, ${ }^{46}$ so it is important to note that shoot segments were used for the determination of water potential, rather than individual leaves (see the section on 'Materials and methods'). It is therefore possible that the $\Psi_{\mathrm{w}}$ values obtained are actually lower than that of mature leaves in these species. Furthermore, if measurements were made on shoots in which growth had ceased due to WS, the $\Psi_{w}$ of these plants would be higher than WW plants, simply due to leaf composition. Because differences in $\Psi_{w}$ between older and younger leaves is often small, ${ }^{47}$ shoot segments were used because it was extremely difficult to obtain $\Psi_{\mathrm{w}}$ values using a pressure chamber on individual leaves in these species.

Changes in pre-dawn water relations were similar among all accessions (Figure 4). Whereas S. tomentosa plants maintained a similar $\Psi_{\mathrm{W}}$ between WW and WS plants, S. alba plants exhibited reduced $\Psi_{\mathrm{w}}$ during the day (Figure $4 \mathrm{~b}$ ), presumably because the extent of osmotic adjustment in response to the WS was greater in S. alba (Figure 4d). In the WW treatment, the MI S. tomentosa accession was the smallest of the accessions in the experiment (Figures 1 and 2), which likely resulted in a low transpirational demand per plant, allowing this accession to maintain midday $\Psi_{w}$ (Figure $4 b$ ) with a relatively (compared to other accessions) small osmotic adjustment (Figure 4d).

Osmotic adjustment can maintain a high RWC even at low leaf water potential, resulting in maintenance of turgor and prevention of tissue desiccation. ${ }^{48}$ Typically, osmotic adjustment can occur when plants have adequate time for the adaptation. ${ }^{49}$ Osmotic adjustment under WS in all accessions resulted in maintenance ( $S$. tomentosa) or a lowering (S. alba) of total water potential and an increased ability to extract water from the media. At both predawn and midday measurements, and in both WW and WS plants, $\Psi_{\pi 100}$ was lower in S. alba than S. tomentosa (Figure 4c and 4d), which may allow $S$. alba plants to extract more soil water and to maintain more green leaf area (Figure 1). However, this did not result in maintained growth (Figure 2) or net $\mathrm{CO}_{2}$ assimilation (Figure 5a) under WS in this species.

All accessions were able to maintain $\Psi_{\mathrm{p}}$ under WS (Figure $4 \mathrm{e}$ and $4 \mathrm{f})$. In three cases, $\Psi_{\mathrm{p}}$ values are higher in WS plants. This may be due to the method used to obtain $\Psi_{\mathrm{w}}$. As discussed previously, if WW plants had actively growing leaves when $\Psi_{\mathrm{w}}$ was measured, the value obtained may be lower than the equivalent shoots of WS plants that may not have actively expanding leaves with lower $\Psi_{\mathrm{w}}$ than fully expanded leaves. This could result in an artificially high $\Psi_{\mathrm{p}}$ in WS plants. However, the differences in $\Psi_{\mathrm{w}}$ between fully expanded and expanding leaves are likely to be small, ${ }^{47}$ so the data imply a maintenance of turgor in all accessions under WS, rather than an increase in turgor.

Both species had high net $\mathrm{CO}_{2}$ assimilation rates (Figure 5), which is consistent with the observation that they both have high net $\mathrm{CO}_{2}$ assimilation relative to other coexisting deciduous species. ${ }^{50}$ Net $\mathrm{CO}_{2}$ assimilation in these species in the WW treatment (Figure $5 \mathrm{a}$ ) is correlated with their biomass accumulation in this (Figure 2) and past studies. ${ }^{38} \mathrm{Net} \mathrm{CO}_{2}$ assimilation in S. tomentosa is lower than in S. alba (Figure 5a and Supplementary Figure S3) in the accessions used in this study and in another set of plants grown from seed collected in northern Indiana (Supplementary Figure S4). Under WS, net $\mathrm{CO}_{2}$ assimilation was not reduced in S. tomentosa, despite a similar reduction in transpiration to $S$. alba in T-MI (Figure 5). Water use efficiency (net $\mathrm{CO}_{2}$ assimilation/transpiration) was higher in WS plants, but did not differ among accessions in either treatment.

Both species maintained turgor during water stress by osmotic adjustment and reducing water loss through reduced stomatal conductance, which decreased by ca $80 \%$ (Figure 5c). Stomatal closure led to reduced transpiration (Figure $5 \mathrm{~b}$ ), but also likely led to the observed reduction in net $\mathrm{CO}_{2}$ assimilation (Figure 5a) and growth (Figure 2). The reduction of stomatal conductance under WS likely allowed both species to maintain high $\Psi_{\mathrm{w}}$ (Figure 4b), even when root zone water content is very low (Figure $3 \mathrm{~b}$ ). Because these species are able to maintain $\Psi_{\mathrm{w}}$ via stomatal closure, it is likely that they would be able to tolerate long-term water deficit in a landscape situation, perhaps longer than other species that continue to lose water and dehydrate. The rapid wilting of these plants exposed to water stress in small containers suggests that the response to water stress observed in this experiment is possible only when plants have sufficient acclimation time. Despite the reduction in net $\mathrm{CO}_{2}$ assimilation, it appears that there was no damage to the photosynthetic apparatus of WS plants, since chlorophyll fluorescence did not change in response to WS, providing further evidence that both species are able to tolerate water stress. 


\section{CONCLUSIONS}

Both S. alba and S. tomentosa survived water deficits down to $20 \%$ media water content. Although we did not examine recovery in these plants, the RWC (Figure 3 ) and $\Psi_{w}$ of the plants at this low root zone water content suggests that they would have survived upon re-watering because cavitation of xylem vessels at these high $\Psi_{\mathrm{w}}$ are unlikely. ${ }^{51}$ Overall, both species exhibited an isohydric model of drought tolerance by a reduction in stomatal conductance that resulted in maintained leaf water potential and the ability to osmotically adjust to maintain leaf turgor in the WS treatment. This apparent adaptive ability is despite the fact that both species typically grow in wet to flooded soils.

Plants that are able to tolerate drought conditions without wilting are more desirable as landscape plants, ${ }^{5}$ and neither species exhibited wilting during the gradual water stress event in this experiment. Growth was inhibited by water stress, but this would not detract from their landscape potential. However, significant leaf necrosis did occur and to a larger extent on S. tomentosa plants, suggesting that $S$. alba may be better suited for the driest areas of a landscape. While the experimental design employed allowed for a slow dry-down, in a typical landscape loam soil, the decrease in water availability would likely be even slower, perhaps allowing for greater potential to adapt to the reduced water availability. Indeed, field observations of multiple accessions of these species growing under minimal irrigation support the fact that they are capable of growing in soils drier than those of their native habitats. ${ }^{17}$

\section{CONFLICT OF INTERESTS}

The authors have no conflict of interest to report.

\section{ACKNOWLEDGEMENTS}

We would like to thank Possibility Place Nursery and Wildtype Native Plant Nursery for supplying plants, Rob Eddy and Daniel Hahn for assistance with plant growth and maintenance, Michael Gosney for technical advice, data collection assistance and figure formatting, and Robert Joly for reviewing the manuscript.

\section{REFERENCES}

1 Close RE, Kielbaso JJ, Nguyen PV, Schutzki RE. Urban vs. natural sugar maple growth: II. Water relations. J Arboric 1996; 22: 187-192.

2 Ruark GA, Mader DL, Veneman PLM, Tattar TA. Soil factors related to urban sugar maple decline. J Arboric 1983; 9: 1-6.

3 Kaushal P, Aussenac G. Transplanting shock in Corsican pine and cedar of atlas seedlings: Internal water deficits, growth and root regeneration. For Ecol Manag 1989; 27: 29-40.

4 Kozlowski TT, Pallardy SG. Acclimation and adaptive responses of woody plants to environmental stresses. Bot Rev 2002; 68: 270-334.

5 Bell NC, Owen J, Stoven H, Altland J. Selection of drought-tolerant shrubs for temperate Mediterranean climates. Acta Hort 2013; 980: 111-117.

6 Villar-Salvador P, Planelles R, Oliet J, Penuelas-Rubira JL, Jacobs DF, Gonzalez M. Drought tolerance and transplanting performance of Holm oak Quercus ilex seedlings after drought hardening in the nursery. Tree Physiol 2004; 24: 11471155.

7 Helfand HE, Park JS, Nassauer Jl, Kosek S. The economics of native plants in residential landscape designs. Landsc Urban Plan 2006; 78: 229-240.

8 McMahan LR. Understanding cultural reasons for the increase in both restoration efforts and gardening with native plants. Nat Plants J 2006; 7: 31-34.

9 West R. Restoring land, community, and soul. Mich Q Rev 2001; 40: 190-207.

10 Kauffman GJ, Vonck KJ. Frequency and intensity of extreme drought in the Delaware Basin, 1600-2002. Water Resources Res 2011; 47: W05521.

11 Sun H, Kopp K, Kjelgren R. Water-efficient urban landscapes: Integrating different water use categorizations and plant types. HortScience 2012; 47: 254-263.

12 Richards MR, Kupp LA, Kjelgren R, Rasmussen VP. Selection and budding propagation of native bigtooth maple for water-conserving landscapes. HortTechnology 2012; 22: 669-676.

13 St.Hilaire R, Arnold MA, Wilkerson DCet al Efficient water use in residential urban landscapes. HortScience 2008; 43: 2081-2092.
14 García-Navarro MC, Evans RY, Montserrat RS. Estimation of relative water use among ornamental landscape species. Sci Hort 2004; 99: 163-174.

15 Levitt DG, Simpson JR, Tipton JL. Water use of two landscape tree species in Tucson, Arizona. J Am Soc Hort Sci 1995; 120: 409-416.

16 Scheiber SM, Gilman EF, Sandrock DR, Paz M, Wiese C, Brennan MM. Postestablishment landscape performance of Florida native and exotic shrubs under irrigated and nonirrigated conditions. HortTechnology 2008; 18: 59-67.

17 Mickelbart MV, Gosney MJ, Stanton KM. Evaluation of accessions of Spiraea alba and Spiraea tomentosa in Indiana. Nat Plants J 2013; 14: 17-23.

18 Symes M. Charles Hamilton's plantings at Painshill. Gard Hist 1983; 11: 112-124.

19 Mickelbart MV, Gosney MJ, Stanton KM. Evaluation of Spiraea alba and Spiraea tomentosa as potential landscape plants in Indiana. Indiana Nurs Landsc News 2012; 72: $18-20$.

20 Lubell JD. Evaluating landscape performance of six native shrubs as alternatives to invasive exotics. HortTechnology 2013; 23: 119-125.

21 Braun LE. Forests of the Illinoian till plain of southewestern Ohio. Ecol Monogr 1936; 6: 89-149.

22 Gates FC. The bogs of northern lower Michigan. Ecol Monogr 1942; 12: 213-254.

23 Kollmann J, Rasmussen KK. Succession of a degraded bog in NE Demnark over 164 years-monitoring one of the earliest restoration experiments. Tuexenia 2012; 32: 67-85.

24 McPhee K, Garnas J, Drummond F, Groden E. Homopterans and an invasive red ant, Myrmica rubra L., in Maine. Environ Entomol 2012; 41: 59-71.

25 Bried JT, Edinger GJ. Baseline floristic assessment and classification of pine barrens vernal ponds. J Torrey Bot Soc 2009; 136: 128-136.

26 Fielder AK, Landis DA. Attractiveness of Michigan native plants to arthropod natural enemies and herbivores. Environ Entomol 2007; 36: 751-765.

27 Koning $\mathrm{CO}$. Vegetation patterns resulting from spatial and temporal variability in hydrology, soils, and trampling in an isolated basin marsh, New Hampshire, USA. Wetlands 2005; 25: 239-251.

28 Stocker M, Gilbert FF, Smith DW. Vegetation and deer habitat relations in southern Ontario: classification of habitat types. J Appl Ecol 1977; 14: 419-432.

29 Ranney TG, Bir RE, Powell MA, Bilderback T. Qualifiers for quagmires: Landscape plants for wet sites. NC State Univ Hort Inf Leaflet 1998; 646: 3.

30 Pope N, Harris TB, Rajakaruna N. Vascular plants of adjacent serpentine and granite outcrops on the Deer Isles, Main, U.S.A. Rhodora 2010; 112: 105-141.

31 Smith SM, Roman CT, James-Pirri MJ, Chapman K, Portnoy J, Gwilliam E. Responses of plant communities to incremental hydrologic restoration of a tide-restricted salt marsh in southern New England Massachusetts, U.S.A. Restor Ecol 2008; 17: 606618.

32 Wilcox DA. The effects of deicing salts on vegetation in Pinhook Bog, Indiana. Can J Bot 1986; 64: 865-874.

33 Cullina W. Native Trees Vines and Shrubs. A Frances Tenenbaum Book. Boston, MA: Houghton Mifflin Company, 2002.

34 Darbyshire SJ. Inventory of Canadian Agricultural Weeds. Ottawa: Agriculture and Agri-Food Canada, 2003.

35 Meilleur A, Véronneau H, Bouchard A. Shrub propagation techniques for biological control of invading tree species. Environ Manag 1997; 21: 433-442.

36 Williams CE, Moriarity WJ, Walters GL. Overstory and herbaceous layer of a riparian savanna in northwestern Pennsylvania. Castanea 1999; 64: 90-97.

37 Girardin M-P, Tardif J, Bergeron Y. Gradient analysis of Larix laricina dominated wetlands in Canada's southeastern boreal forest. Can J Bot 2001; 79: 444-456.

38 Stanton KM, Weeks S, Dana MN, Mickelbart MV. Light exposure and shade effects on growth, flowering, and leaf morphology of Spiraea alba Du Roi and Spiraea tomentosa L. HortScience 2010; 45: 1912-1916.

39 Mickelbart MV, Gosney MJ, Camberato J, Stanton KM. Soil pH effects on growth and foliar nutrient concentrations of Spiraea alba Du Roi and Spiraea tomentosa L. HortScience 2012; 47: 902-906.

40 Bell LW, Williams $\mathrm{AH}$, Ryan $\mathrm{MH}$, Ewing MA. Water relations and adaptations to increasing water deficit in three perennial legumes, Medicago sativa, Dorycnium hirsutum and Dorycnium rectum. Plant Soil 2007; 290: 231-243.

41 Galmés J, Cifre J, Medrano H, Flexas J. Modulation of relative growth rate and its components by water stress in Mediterranean species with different growth forms. Oecologia 2005; 145: 21-31.

42 Franco JA, Banon S, Vicente MJ, Miralles J, Martinez-Sanchez JJ. Root development in horticultural plants grown under abiotic stress conditions-a review. J Hort SCi Biotech 2011; 86: 543-556.

43 Jiménez S, Dridi J, Gutiérrez D et al Physiological, biochemical and molecular responses in four Prunus rootstocks submitted to drought stress. Tree Physiol 2013; 33: 1061-1075.

44 Chaves MM, Pereira JS, Maroco J et al How plants cope with water stress in the field. Photosynthesis and growth. Ann Bot 2002; 89: 907-916.

45 Small E. Water relations of plants in raised sphagnum peat bogs. Ecology 1972; 53 $726-728$ 
46 Knipling EB. Effect of leaf age on water deficit-water potential relationships of dogwood leaves growing in two environments. Physiol Plant 1967; 20: 65-72.

47 Saito T, Naiola BP, Terashima I. Conservative decrease in water potential in existing leaves during new leaf expansion in temperate and tropical evergreen Quercus species. Ann Bot 2007; 100: 1229-1238.

48 Morgan JM. Osmoregulation and water stress in higher plants. Ann Rev Plant Physiol 1984; 35: 299-319.

49 Levitt J. Relationship of dehydration rate to drought avoidance, dehydration tolerance and dehydration avoidance of cabbage leaves, and to their acclimation during drought-induced water stress. Plant Cell Environ 1985; 8: 287-296.

50 Small E. Photosynthetic rates in relation to nitrogen recycling as an adaptation to nutrient deficiency in peat bog plants. Can J Bot 1972; 50: 2227-2233.
51 West AG, Hultine KR, Jackson TL, Ehleringer JR. Differential summer water use by Pinus edulis and Juniperus osteosperma reflects contrasting hydraulic characteristics. Tree Physiol 2007; 27: 1711-1720.

cc)(ㅇ) This work is licensed under a Creative Commons Attribution-

BY No ND NonCommercial-NoDerivs 3.0 Unported License. The images or other third party material in this article are included in the article's Creative Commons license, unless indicated otherwise in the credit line; if the material is not included under the Creative Commons license, users will need to obtain permission from the license holder to reproduce the material. To view a copy of this license, visit http:// creativecommons.org/licenses/by-nc-nd/3.0/

Supplemental Information for this article can be found on the Horticulture Research website (http://www.nature.com/hortres). 